\title{
Deslocamentos da arte
}

Luiz Sérgio de Oliveira*

http://dx.doi.org/10.22409/poiesis.1829.175187

RESUMO: Centradas nas noções de encontros, as residências artísticas têm, por sua própria natureza, a ênfase no processo de deslocamento do artista, ora dispensando, ora valorizando a produção de objetos artísticos. Neste sentido, muitas vezes os resíduos ou vestígios dessas residências parecem forçados nos espaços expositivos, sem que ocorra uma avaliação mais profunda acerca da eficácia e da relevância dessa transposição das experiências das residências artísticas para os espaços de exposição. Neste estudo, analisamos a participação do artista carioca Hélio Carvalho no programa de residências artísticas no Hospital da Mulher Heloneida Studart, em São João de Meriti, realizado em 2016, e seu desdobramento em mostra no Centro Municipal de Arte Hélio Oiticica, Rio de Janeiro.

PALAVRAS-CHAVE: práticas artísticas efêmeras, residências artísticas, objeto artístico, Hélio Carvalho

ABSTRACT: Centered on the notions of encounters, artistic residences have, by their very nature, the emphasis on the process of displacement of the artist, sometimes dispensing, or at times valuing the production of artistic objects. In this sense, residues or vestiges of these residences often appear forced in the exhibition spaces, without a deeper evaluation of the effectiveness and relevance of this transposition of the experiences of the artistic residences to the exhibition spaces. In this study, we analyze the participation of the carioca artist Hélio Carvalho in the program of artistic residencies at the Hospital for the Women Heloneida Studart, in São João de Meriti, in 2016, and its exhibition at the Hélio Oiticica Municipal Art Center, Rio de Janeiro.

KEYWORDS: ephemeral artistic practices, artistic residences, artistic object, Hélio Carvalho

\footnotetext{
* Luiz Sérgio de Oliveira é artista e Professor Titular de Artes / Poéticas Contemporâneas da Universidade Federal Fluminense. Doutor em Artes Visuais (História e Teoria da Arte) pelo PPGAV-EBA-UFRJ e Mestre em Arte pela Universidade de Nova York (NYU). É professor do Programa de Pós-Graduação em Estudos Contemporâneos das Artes (PPGCA-UFF) e editor da Revista Poiésis (PPGCA-UFF) entre 2011 e 2014 e em 2017. E-mail: luizsergiodeoliveira.br@gmail.com.
} 


\section{Heteronomia do contemporâneo}

Ao longo de vários meses do ano de 2016, o artista Hélio Carvalho embrenhou-se por uma realidade que não the era familiar para, no universo da cidade de São João de Meriti, Baixada Fluminense, desenvolver um projeto artístico. Tratava-se de um programa de residências artísticas em uma unidade hospitalar e ambulatorial da Secretaria de Estado de Saúde do Rio de Janeiro (SES/RJ) - Hospital da Mulher Heloneida Studart (HMHS), distante aproximadamente 30 quilômetros do Centro do Rio de Janeiro'. Enquanto, em um passado não muito distante, aos artistas pareciam bastar os espaços de seu ateliê e de seu isolamento, em inúmeras manifestações da arte contemporânea isso já não parece ser o bastante.

Houve um tempo em que prevalecia certa convergência entre a arte que se fazia autônoma e o sistema de arte construído para lhe dar suporte em sua saga pela autonomia. Neste sentido, sistema e arte compartilhavam a mesma orientação que havia elegido o mundo da arte como o destino imperturbável da produção dos artistas. Mesmo que os produtores de arte se aventurassem em sobrevoos no mundo que se organiza para além do mundo da arte, as ideias, questões, temas e imagens pinçadas desse mundo deveriam necessariamente ser filtradas ou transmutadas para que granjeassem um lugar no mundo da arte. À arte e ao sistema que Ihe dava suporte não interessava que a vida in natura adentrasse neste universo sempre seleto e discriminatório. De acordo com os preceitos do moderno, era esperado que a criação do artista fosse originária de certo distanciamento das banalidades do mundo, era desejado que essa criação estivesse suficientemente protegida das secularidades da vida, garantindo-se assim a autonomia da arte.

O cenário da arte contemporânea, entretanto, é definido pela heteronomia, sendo o artista solicitado a interagir com as coisas do mundo e a se deixar contaminar pelo mundo mundano, um mundo enriquecido pelo ordinário da vida e do cotidiano. Essa produção de arte, franqueada aos encontros e aos diálogos, parece tomar emprestado os versos da poeta para convidar a mundanalidade da vida: "Entre por essa porta agora | E diga que me adora | Você tem meia hora | Pra mudar a minha vida | Vem vam'bora | Que o que você demora | É o que o tempo leva".2

Pode-se argumentar, no entanto, que parte dessa produção contemporânea que se apresenta como aberta aos diálogos e às contaminações, caracterizada por práticas que enfatizam o 
processo, a imaterialidade e o efêmero na arte, parece igualmente seduzida pelos cantos de sereia do sistema de arte, como se os encontros com esse outro que se desconhece servisse para dar um novo sentido a uma produção de arte que persegue seu circuito tradicional de exposições de arte em galerias, museus e centros culturais. Mesmo que a persistência do culto ao objeto artístico pareça um tanto imprópria em tempos marcados pela volatilidade do virtual e pela ênfase nas trocas em torno do impalpável, não se pode desconhecer o quanto o campo da arte é conservador menos em seu aspecto patrimonialista, e parece se manter atado às lógicas do moderno, o que nos traz de volta ao pensamento de Habermas quando assevera que "o modernismo está morto mas continua dominante". (apud DUNN; LEESON, 1997, p. 26) Neste cenário de atravessamentos, avanços e recuos se encaixam as incertezas e hesitações que, de alguma maneira, acompanharam e enriqueceram o programa de residências artísticas do Hospital da Mulher Heloneida Studart (HMHS), do qual destacamos a participação de Hélio Carvalho.

\section{Deslocamento de práticas efêmeras para os espaços expositivos}

Como se não bastassem os desafios enfrentados pelos artistas em seu processo de deslocamento para realidades que não conhecem ou que conhecem apenas superficialmente, de "ouvir dizer", o programa de residências artísticas no Hospital da Mulher Heloneida Studart (HMHS) caracterizou-se ainda por uma história que pode ser contada às avessas, de trás para frente: como consequência de sua seleção em um edital de ocupação dos espaços expositivos da Secretaria Municipal da Cultura da Prefeitura da Cidade do Rio de Janeiro, a realização de uma exposição no Centro Municipal de Arte Hélio Oiticica (CMAHO), Centro do Rio de Janeiro, impôs-se como compromisso de se apresentar os resultados das residências artísticas. Havia, portanto, uma inversão no programa de residências artísticas do HMHS que, desde a primeira hora, assumia a responsabilidade de trazer os frutos das trocas provocadas pelos artistas, independentemente da impalpabilidade desses encontros, para os espaços de exposição do CMAHO. Neste sentido, antes mesmo do início do programa no HMHS e na cidade de São João de Meriti, já havia um compromisso firmado e uma mostra no horizonte do programa.

No artigo Lessons in Futility - Francis Alÿs and the Legacy of May '68, o crítico, teórico e professor da Universidade da Califórnia (San Diego) Grant Kester elabora sobre elementos 
que podem nos ajudar em nossa reflexão crítica do programa de residências artísticas no HMHS, em especial em seu deslocamento para a exposição no Centro Municipal de Arte Hélio Oiticica. No texto, Kester analisa a instalação do artista belgo-mexicano Francis Alÿs no Hammer Museum de Los Angeles em torno do projeto Cuando la fe mueve montañas / When Faith Moves Mountains, entendido por Kester como uma performance e realizado pelo artista e colaboradores em 2002 nas cercanias da cidade de Lima, Peru:

A criação desta performance envolveu semanas de esforço e a composição de uma rede social e organizacional complexa. A apresentação no museu, entretanto, focou primeiramente no espetáculo dos voluntários cavando na areia. A instalação no Hammer Museum em Los Angeles centrou na projeção de um filme de 15 minutos documentando a busca inicial de Alÿs pela locação, a chegada dos voluntários e o efetivo trabalho de cavação. Além disso, havia fotografias da performance ao lado de inúmeros textos curtos e de trocas de e-mails entre Alÿs e seus colaboradores, Cuauhtémoc Medina e Rafael Ortega, expostos sob plexiglás em um conjunto de mesas baixas. As imagens incluíam uma fotografia assinada de Alÿs, Medina e Ortega posando juntos no local da performance com megafones e câmeras, enquanto se preparavam para dirigir o trabalho de 500 voluntários, a maioria jovens estudantes universitários de Lima, vestindo camisetas com o logotipo do projeto. Embora o vídeo inclua comentários de vários estudantes voluntários (não identificados), a instalação da Alÿs faz pouco para identificar a natureza de sua participação ou de seu investimento particular na tarefa sisifiana a eles atribuída pelo artista. Eles foram convocados por Alÿs não como colaboradores, mas como corpos para ilustrar uma "alegoria social" sobre o inevitável fracasso da América Latina em alcançar sua modernização. (KESTER, 2009, p. 414)

A análise de Grant Kester das relações de colaboração que se estabeleceram no projeto de Francis Alÿs no Peru poderia ser deslocada e aplicada, com os devidos reparos referentes aos elementos de descrição do projeto e de sua apresentação no museu, para muitas práticas colaborativas, processuais e efêmeras que compõem o universo da arte crítica na contemporaneidade, quando transladadas para os espaços do circuito tradicional da arte. Lastreado no atendimento de interesses difusos, o projeto de Francis Alÿs, independentemente das intencionalidades e dos compromissos políticos e/ou ideológicos do artista, foi catapultado para o circuito de arte em uma armadilha que insiste em desconhecer que certos projetos de arte estão atados às localidades, incluindo-se seus contextos sócio-político-culturais em relação aos quais foram concebidos e nos quais foram realizados. 

Em acrobacias que tentam desconsiderar os riscos inerentes à operação, esses projetos, ou melhor, seus resíduos ou vestígios, são lançados nos espaços expositivos sem que se faça uma efetiva avaliação da eficácia e da relevância carreadas nesse translado para os espaços de exposição. Conforme discutido em outra oportunidade, o museu de arte (e seus congêneres) "é uma instituição que busca criar universalidades, que visa criar universos de neutralidade e de descontextualização capazes de abrigar artefatos e obras de arte que representam viagens no tempo e no espaço de um homem universal imaginado" (OLIVEIRA, 2017, p. 205) e que, como consequência, vai na contramão do escopo de projetos de arte baseados em contextos específicos, entre os quais se situam o programa de residências artísticas do Hospital da Mulher Heloneida Studart (HMHS).

Neste sentido, é justamente nos contextos que deram origem a esses projetos de arte que esses mesmos projetos

encontram sua "verdade" e se enriquecem com o encontro com as singularidades do lugar, da realidade e daquele "mundo" específico. A transposição desses encontros para os espaços amolecentes e neutralizadoras do museu de arte, em geral em aparições fantasmáticas que se materializam em arremedos de realidade, aplaca a presença e a força do mundo, destituindo a experiência da arte de sua presença no mundo mundano. (OLIVEIRA, 2017, p. 204-205)

Melhor seria se pudéssemos simplesmente deixar os projetos de arte lá onde tiveram seu acontecimento, articulados em torno de encontros com grupos e contextos específicos, e que assim continuassem a reverberar na memória de sua audiência primária, formada pelos colaboradores, entendidos igualmente como público privilegiado, além de outras pessoas que, de uma maneira ou de outra, estivessem presentes no ato de sua criação/realização. Para além dessas reverberações junto ao primeiro grupo imediato, apenas os registros da história que, ao contrário do que sugerem as exposições tentam criar vínculos causais com o projeto de arte, funcionam como anotações em favor de uma memória histórica e da disseminação de práticas que, de acordo com critérios fundados tanto na tradição quanto na invenção, mereçam ter sua relevância ressaltada e preservada.

O desejo de simplesmente deixar os projetos de arte lá onde tiveram seu acontecimento não se configurou como uma possibilidade para o programa de residências artísticas no Hospital da Mulher Heloneida Studart (HMHS), uma vez que, por força do edital do qual advieram 
os recursos para sua realização, estabeleceu-se a demanda por uma exposição no Centro Municipal de Arte Hélio Oiticica. Junto a essa demanda estabelecida já no ponto de partida do programa, um enorme desafio se impôs aos artistas e curadores envolvidos: como desviar-se da força centralizadora que um projeto de exposição de arte exerce sobre corações e mentes de artistas, curadores e outros agentes do mundo da arte? Como evitar que a exposição viesse a angariar o protagonismo do programa e assim se sobrepusesse às práticas imprecisas e fluidas da experiência das residências em si?

\section{O projeto $O$ Deambulatório de Hélio Carvalho}

Para impedir que a atividade projetada para o Centro Municipal de Arte Hélio Oiticica - a exposição de arte - viesse a dominar o programa, curadores e artistas decidiram que as ações se concentrariam preferencialmente no HMHS, enfatizando a interação direta dos artistas com as comunidades (diversas) que frequentam seu cotidiano hospitalar, permitindo que "aquele cotidiano banhasse e contaminasse suas experiências de vida, de artista e sua arte". (OLIVEIRA, 2016, p. 14) Por outro lado, mesmo entendida como um aspecto residual do programa, a mostra prevista para o Centro Municipal de Arte Hélio Oiticica se apresentava como uma possibilidade de disseminação das experiências no HMHS, de maneira que um público distante, o "público secundário" (DOHERTY, 2004, p. 9)3, pudesse tomar ciência da experiência vivenciada nas residências artísticas no Hospital da Mulher Heloneida Studart.

Assim, os parceiros dos artistas, aqueles que podem ser identificados como colaboradores ou coautores, como preferem alguns teóricos, se transformaram também em audiência privilegiada desses projetos de arte produzidos no HMHS. Por outro lado, o público de habitués da arte, aquele "ao qual normalmente se recorre em busca de validação" (HELGUERA, 2011, p. 43), teria acesso apenas aos vestígios de um processo de arte que foi consumido em um tempo preciso, que poderia ser um tempo alongado em meses ou circunscrito a poucos minutos passageiros.

Dos quatro artistas envolvidos no projeto, Hélio Carvalho parece ter se dedicado em especial a essa transposição das ações vivenciadas em São João de Meriti e sua apresentação - inevitavelmente fantasmática - na cidade do Rio de Janeiro, configurando-se como um projeto imprescindível para nossas reflexões. 
As experiências protagonizadas por Hélio Carvalho no hospital de São João de Meriti se deram fundadas em uma intensa interação com os diferentes grupos de servidores e de usuários que compõem o cotidiano do HMHS, desde a montagem do Veículo Deambulatório, dispositivo produzido com partes de equipamentos hospitalares inservíveis e que contou com o auxílio da equipe de manutenção do hospital, à confecção de um "uniforme" com todas as cores do espectro cromático que define, segundo os protocolos hospitalares, as categorias de profissionais atuantes em seu cotidiano. Segundo o artista,

A concepção do uniforme híbrido, com fragmentos que faziam referências aos uniformes de outros profissionais, surgiu desse desejo de ostentar certa identidade, mesmo que provocando um pouco de estranheza inicial. De toda maneira, pilotar o Veículo Deambulatório trajando esta indumentária especial me aproximava do contingente de trabalhadores que também perambulam pelos corredores, realizando suas tarefas específicas, trajando seus uniformes coloridos. ${ }^{4}$

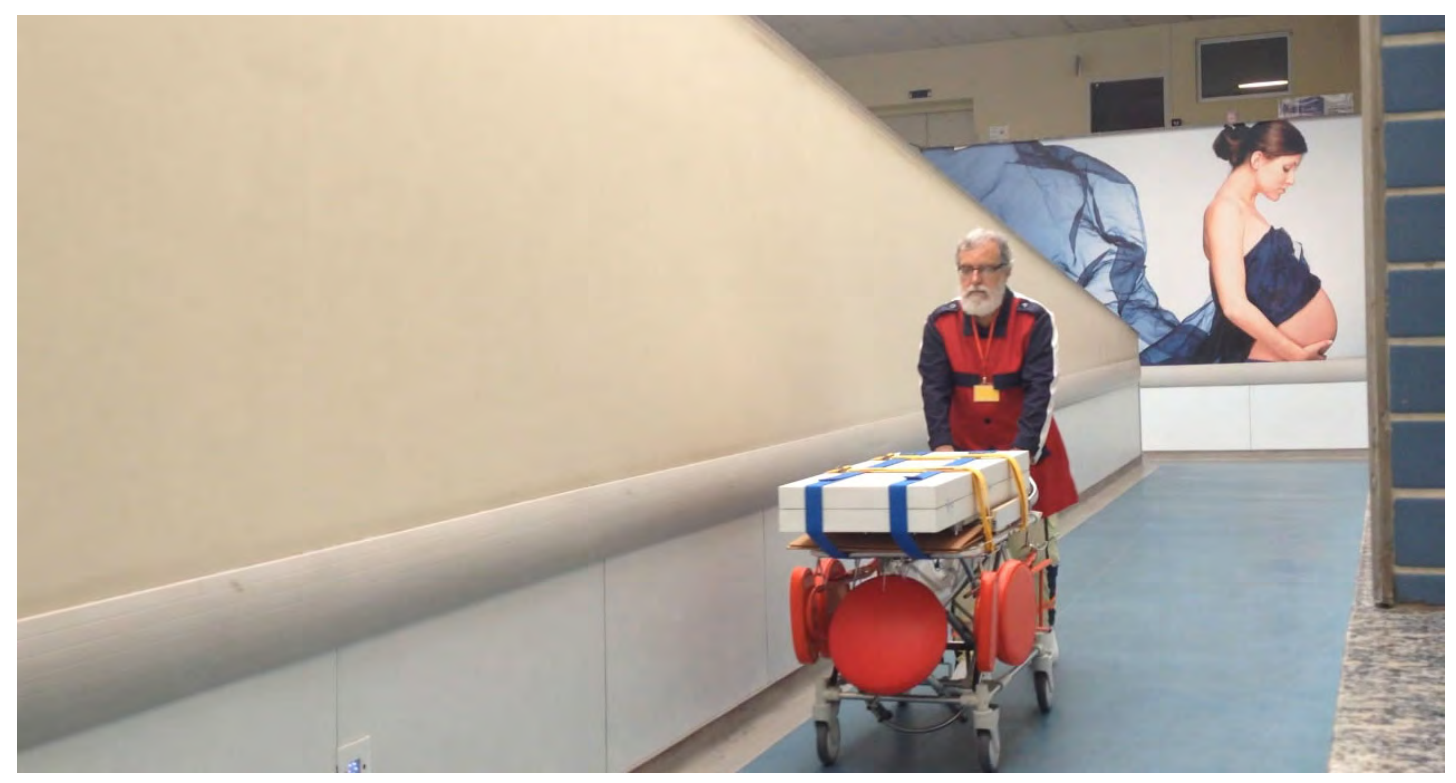

Hélio Carvalho em ação deambulatória no HMHS, 2016.

São João de Meriti

(Foto: Filipe Britto) 
Com esses dois dispositivos básicos - Veículo Deambulatório e Traje para Deambular-, Hélio Carvalho vagou pelos corredores, salas de espera e átrios do HMHS à espreita de possibilidades de encontros e de interação com seus diferentes grupos sociais. E quando essas oportunidades se ofereciam, o artista "estacionava" seu dispositivo, seu Veículo Deambulatório, uma base de apoio para que o artista viesse a entabular conversas e mais conversas com os usuários do ambiente hospitalar, como se assim fosse possível propiciar um distanciamento momentâneo - por certo, precário - de suas ansiedades e seus medos. Hélio Carvalho poderia surgir em qualquer parte do hospital, qualquer lugar poderia ser escolhido pelo artista para a busca de um encontro com aquele que não se conhece e de quem provavelmente reteremos apenas alguns traços evanescentes na memória.

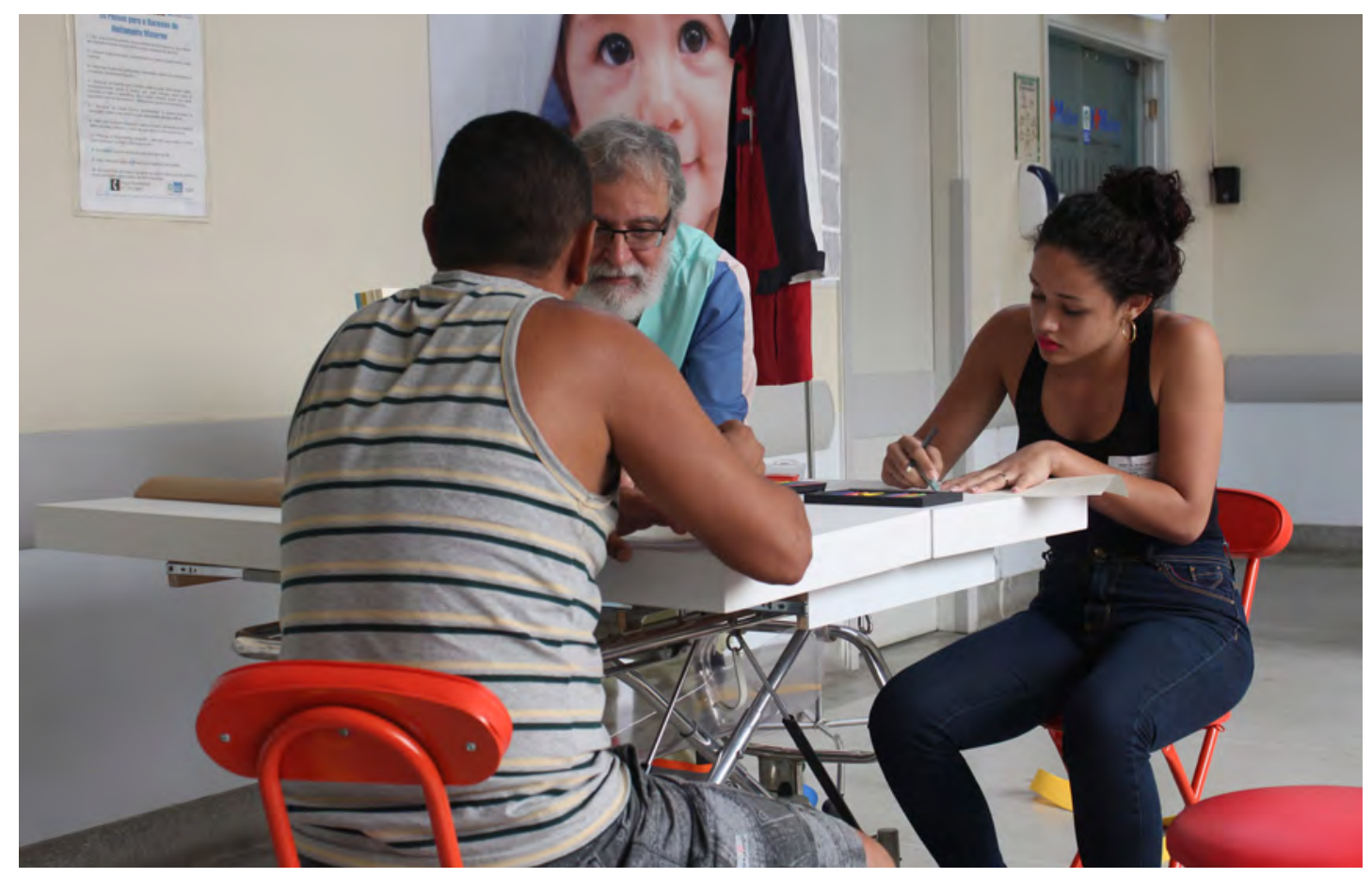

Hélio Carvalho e participantes em O Deambulatório no HMHS, 2016.

São João de Meriti

(Foto: Luiz Sérgio de Oliveira) 
Essas experiências de encontros e de trocas que têm a arte como dispositivo se transformam elas mesmas em práticas de arte a partir da ação e do envolvimento diretos do artista. Como experiências são, como se pode depreender, parte de uma categoria de fenômenos extremamente difíceis de serem retidas ou representadas em qualquer situação ou ambiente diferente daquele exato cenário em que se deram; para essas experiências, parece não haver espelho ou magia capaz de reter sua imagem com alguma exatidão.

O registro das experiências vagantes de Hélio Carvalho pelos corredores hospitalares do HMHS para efeito da exposição no Centro Municipal de Arte Hélio Oiticica, algo que fosse minimamente pareado com a experiência em si, revelar-se-ia como uma impossibilidade, algo que configurar-se-ia como um mero registro anêmico e fantasmático. Nas palavras do próprio artista:

No meu entender, a experiência artística em si concretizou-se de fato, nas ações desenvolvidas no hospital. Quando a mesa-carrinho se instalava momentaneamente em algum corredor do prédio, era como se surgisse ali uma ilha de acolhimento e de encontro, onde as hierarquias eram dissolvidas e se estabeleciam vínculos temporários, mas significativos. O convite aos pacientes e familiares que frequentavam o hospital para participar de uma atividade de expressão artística pelo desenho ou colagem, era o pretexto necessário para que a realidade profunda emergisse em toda sua força e naturalidade. A conversa em torno da mesa, conduzida pelo risco dos lápis de cor, se mostrou capaz de suspender, momentaneamente, as adversidades revelando as possibilidades do compartilhamento. ${ }^{5}$

De maneira a enfrentar essa impossibilidade, o artista parece ter optado por assumir os dois espaços em suas plenas distinções: enquanto no hospital, as ações e os encontros foram vivenciados pelo artista e pelos participantes em um processo de derretimento de instâncias supostamente distintas - arte e vida -, para a exposição no Centro Municipal de Arte Hélio Oiticica o artista optou por "desidratar" os dispositivos empregados nas ações em São João de Meriti - Traje para Deambular e Veículo Deambulatório -, mantendo-os deliberadamente em estado de exposição, inanimados, esvaziados de seus componentes pulsantes e vívidos, expostos ao lado de imagens fotográficas e monitores de vídeo. Assim, o Veículo Deambulatório permaneceu "definitivamente" estacionado no espaço expositivo, enquanto - Traje para Deambular permanecia suspenso, preso em um cabide e fixado à parede da sala de exposição, tomando emprestada da superfície plana da parede sua plena planaridade, 


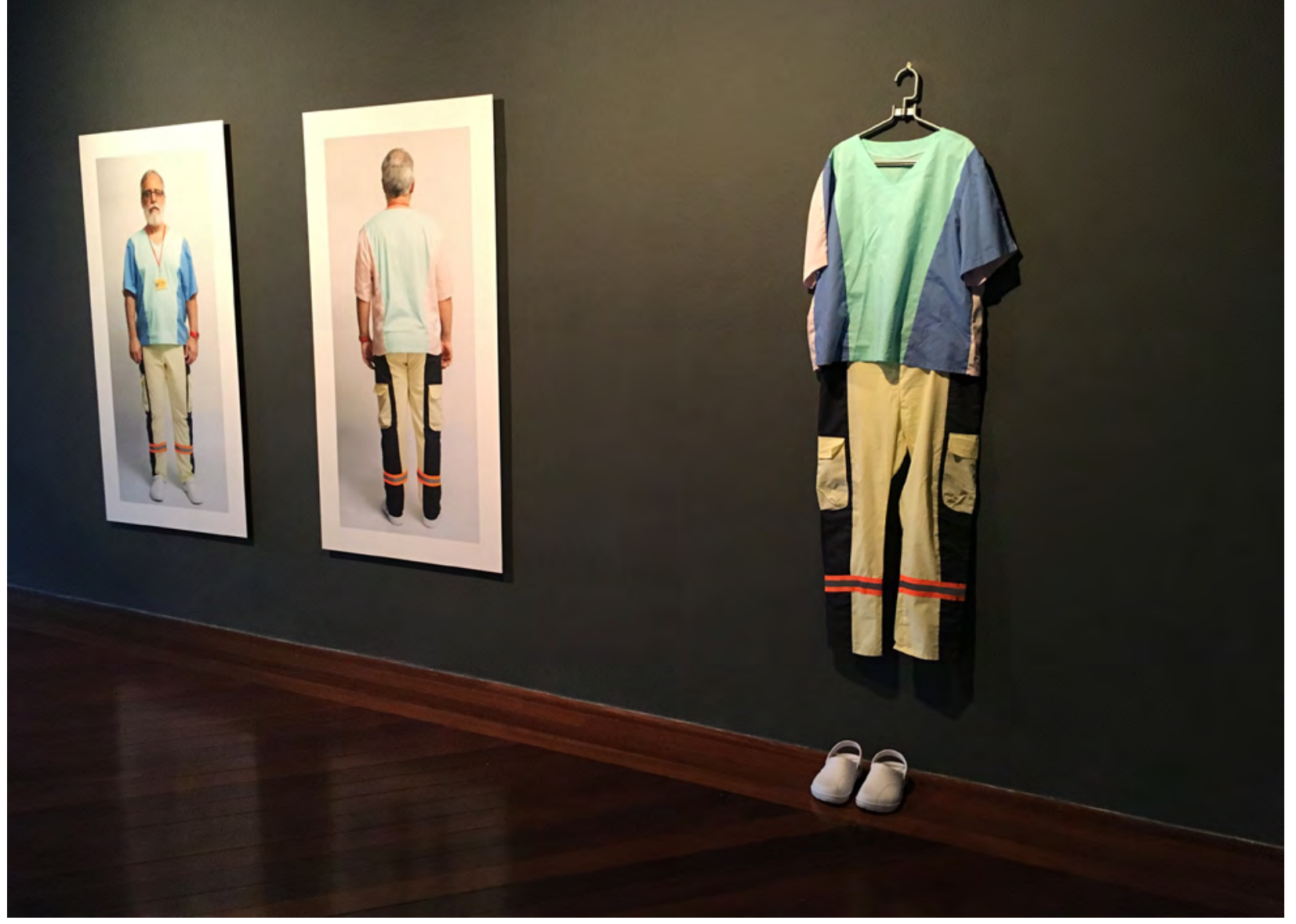

Hélio Carvalho, Traje para Deambular, 2016.

fotografia e materiais diversos; dimensões variadas

Centro Municipal de Arte Hélio Oiticica

(Foto: Luiz Sérgio de Oliveira)

Naquilo que pareceu ser uma tentativa do artista de explicitar as distinções dos cenários com os quais interagia, Hélio Carvalho, depois de se envolver diretamente em encontros delimitados pela impalpabilidade de histórias de vidas plenas de angústias e de esperanças, apresentou no Centro Municipal de Arte Hélio Oiticica os elementos materiais de seu projeto, aqui transmutados em uma instalação. Esses elementos, deliberadamente desprovidos dos fluxos e das pulsações da vida, descarnados e descorporificados, pareciam reafirmar que as práticas da arte contemporânea que enfatizam os processos de encontro e de trocas no campo social simplesmente parecem não caber (verdadeiramente) nos ambientes desidratados das instituições de arte. 


\section{Referências}

DOHERTY, Claire. The New Situationists. In DOHERTY, Claire (ed.). Contemporary Art: From Studio to Situation. Londres: Black Dog Publishing, 2004, p. 7-13.

DUNN, Peter; LEESON, Loraine. The Aesthetics of Collaboration. Art Journal (College Art Association), primavera 1997, pp. 26-37.

HELGUERA, Pablo Educação para uma arte socialmente engajada. In HELGUERA, Pablo; HOFF, Mônica (orgs.). Pedagogia no campo expandido. Porto Alegre: Fundação Bienal de Artes Visuais do Mercosul, 2011, pp. 35-44.

KESTER, Grant. Lessons in Futility - Francis Alÿs and the Legacy of May '68. Third Text, v. 23, n. 4, jul. 2009, pp. 407-420.

OLIVEIRA, Luiz Sérgio de. Arte contemporânea e o jogo das sete dúvidas. In CERBINO, Beatriz; OLIVEIRA, Luiz Sérgio de; TABORDA, Tato (orgs.). Subversões de protocolos :uso impróprio. Niterói: PPGCA-UFF, 2017, pp. 203-216.

OLIVEIRA, Luiz Sérgio de. Nos limites da arte. (texto de catálogo de exposição) In RIVERA, Tania; OLIVEIRA, Luiz Sérgio de. Nos limites do corpo: residência artística no Hospital da Mulher Heloneida Studart. Rio de Janeiro: Relacionarte, 2016, pp. 12-14.

\section{Notas}

1 Ao lado das artistas Cristina Salgado, Gabriela Mureb e Roberta Barros, Hélio Carvalho participou do programa de residências artísticas no Hospital da Mulher Heloneida Studart. O projeto teve a curadoria de Tania Rivera e Luiz Sérgio de Oliveira, tendo sido contemplado no edital de ocupação dos equipamentos culturais na Secretaria Municipal da Cultura da cidade do Rio de Janeiro. Como parte do projeto, a exposição No limite do corpo no Centro Municipal de Artes Hélio Oiticica, Rio de Janeiro, no período de 5 de novembro de 2016 a 18 de fevereiro de 2017.

2 Trecho da letra da canção Vam'bora de autoria de Adriana Calcanhoto, gravada no álbum Marítimo, quarto disco da artista (Columbia Records, 1998).

3 De acordo com Claire Doherty, a "audiência secundária" seria formada pela segunda camada de público de um projeto de participação comunitária, em seguida às comunidades participantes transformadas em coautores.

4 Hélio Carvalho em depoimento para o autor.

5 Depoimento do artista para o autor. 